\title{
The psychological impact of a negative BRCA1 test: A wolf in sheep's clothing?
}

The new era of genetic testing for breast cancer susceptibility began soon after the Breast Cancer 1 and Breast Cancer 2 (BRCA1 and BRCA2) genes were identified in 1994 and 1995. 1,2 The possibility that a simple blood test could identify high-risk women became a powerful model for cancer prevention and control in the biomedical community. ${ }^{3}$ However, it soon became clear that incorporating cancer susceptibility testing into clinical practice was not straightforward, and several groups raised important questions about the clinical and ethical application of such DNA-based tests. Indeed, the American Society of Human Genetics and the National Advisory Council for Human Genome Research recommended that testing should be limited to participants in well-designed scientific studies until the clinical uncertainty of genetic testing was addressed., 4

While BRCA1/2 testing has been shown to be important for high-risk families, ${ }^{6,7}$ several issues continue to be unresolved for susceptibility testing in the general population. Risk assessment for an individual depends upon genetic factors such as family tree structure, locus and allelic heterogeneity, penetrance of specific alleles, and the prevalence of mutations within specific populations. Other issues are psychosocial and include the psychological impact of testing, privacy, and potential discrimination by insurance providers and employers. Thus, the decision to undergo susceptibility testing is a complex process in which each individual must weigh the risks and benefits of the genetic and psychosocial factors.

In this issue of Genetics in Medicine, Friedman et al. ${ }^{8}$ offer evidence to further our understanding of the psychological impact of genetic testing for breast cancer susceptibility. They found minimal psychological distress after receiving negative or uninformative results for the BRCA1 185delAG mutation in Ashkenazi Houston residents who volunteered for a community-based genetic testing program. This screening program is described in detail in a previous paper by the group. ${ }^{9}$ In this study, 289 subjects attended an educational forum on breast cancer genetics and donated a blood sample for genetic testing for the $185 \mathrm{del} A \mathrm{G}$ mutation in the BRCAl gene. Two-hundred eightythree subjects ( $98 \%$ ) were notified by letter of their negative or uninformative result. Of this group, 199 subjects completed two psychological measures at baseline, 1 month, and 6 months after testing. The authors used the Profile of Mood States-Short Form (POMS-SF) to measure the subjects' general distress and anxiety and the Impact of Events Scale (IES) to measure the intrusiveness of cancer distress on daily life. The initial IES scores were low in both groups, indicating little impact of cancer distress.
Importantly, after the disclosure of a negative or uninformative test result, the scores did not significantly increase or decrease. The authors then compared the scores between cases with no personal or family history ("average risk") and cases with a personal or family history of breast or ovarian cancer ("increased risk"). As expected, the higher risk group significantly differed from the average risk group by having higher IES scores at each time-point. However, disclosure of negative or uninformative results did not result in a marked increase or decrease in psychological distress, even in the group with a positive personal or family history. When both groups were retested six month later, there was a slight decrease in the IES scores for average risk subjects and relatively little change for the higher risk group.

From a clinical standpoint, it is not clear that these results are applicable to the general non-Ashkenazi population or to individual patients who are seeking genetic testing from genetic counselors or health care providers. This is because the clinical implications of an uninformative or negative result for cancer gene testing are difficult to ascertain. A positive or negative $\mathrm{BRCAl} / 2$ test is dependent upon the prior probability of finding a mutation within an affected individual in the family. Ideally, the most informative result for an individual with a negative test occurs in the context of a known pathologic mutation in a close relative. On the other hand, the least informative situation occurs when a healthy woman tests negative as part of a population-screening program. Most clinical testing situations fall somewhere between these two possibilities, so that interpreting a negative result within the context of the family tree is essential to the overall risk analysis and medical management for at-risk women.

The Friedman ${ }^{8}$ study is a targeted screening study of the Houston area Ashkenazi Jewish community for a single genetic mutation in the BRCAI gene. Although each subject consented to participate, an individualized risk analysis based on the family history of breast or ovarian cancer was not part of the protocol. Instead, the authors grouped cases into average risk (no family history) and increased risk (positive personal or family history for breast and/or ovarian cancer). After BRCAl testing, a "not informative" result was one in which the individual had a negative $185 \mathrm{delAG}$ test and a personal or family history of breast or ovarian cancer. Of the 61 uninformative cases, $28 \%$ had a personal history of breast or ovarian cancer, $13 \%$ had both a personal and family history, and $58 \%$ had a positive family history. The recipient of an uninformative result may not 
realize that despite the genetic test result, their personal risk factors and family history might indicate a more substantial risk for breast or ovarian cancer. Friedman et al. ${ }^{8}$ informed their higher risk participants about the availability of genetic counseling, but it is not known whether any participants were seen for these specialized clinical services. Thus, the American Cancer Society (ACS) screening guidelines that were included with the disclosure letter may not be adequate for every woman in this higher risk group.

Although not the fault of the authors, this study also suffers from the clarity of hindsight provided by new genetic discoveries made after the testing and notification process for this study began. In addition to the 185 delAG mutation, two other highly prevalent mutations in the BRCA1 and BRCA2 gene have been identified. ${ }^{10}$ Thus, a more complete testing protocol would also include the 5382insC mutation in BRCAl and the 6174delT in BRCA2. The prevalence for all three mutations is estimated to be about 1 out of 50 Ashkenazim. As Richards et al. ${ }^{9}$ comment in their initial description of this project, the participants consented to additional testing on the $6174 \mathrm{del} T$ mutation without follow-up notification, and seven additional cases were shown to be heterozygous for the $6174 \mathrm{delT}$ mutation. Thus, this screening study clearly illustrates that an uninformative genetic test can mask an important pathologic genetic finding in an individual tested as part of a screening program.

How can we best understand the meaning of a negative or uninformative result for breast cancer? The psychosocial impact of testing for breast cancer has received a great deal of attention in the scientific literature and national media. First, does notification of a test result cause undue anxiety? In studies of high risk kindreds, women who learn that they are carriers for a breast cancer susceptibility allele have a moderate increase in their anxiety about developing breast or ovarian cancer. Conversely, women who learn that they are not carriers of a pathologic allele usually have a reduction in anxiety for their risk for breast cancer. ${ }^{11}$ Second, does a negative result provide women with false assurance about the future? Clearly, all women with an uninformative genetic test should continue to follow appropriate screening guidelines since a specific BRCA1 or BRCA2 test can not guarantee that an individual will or will not develop breast or ovarian cancer. Unfortunately, there are few, if any, follow-up studies of cancer screening behaviors of women with negative tests. ${ }^{12}$ Thus, it is not known whether false assurance of a negative test is a real or theoretical concern for breast cancer testing.

This study provides important evidence that notification of a negative or uninformative $185 \mathrm{delAG}$ result is not excessively harmful to members of the Ashkenazi community. In other words, the initial impact of notification did not cause undue harm to these individuals. Did these subjects suffer from a false assurance from this negative result? Friedman et al. ${ }^{8}$ did not specifically address the question of impact of a negative uninformative result on cancer screening behaviors. However, they have established an attractive framework in which to study this question in the future.

\section{REFERENCES}

1. Miki Y, Swensen J, Shattuck-Eidens D, Futreal PA, Harshman K, Tavtigian S, Liu Q, Cochran C, Bennett LM, Ding W, Bell, R, Rosenthal J, Hussey C, Tran T, McClure M, Frye C, Hattier T, Phelps R, Haugen-Strano A, Katcher H, Yakumo K, Gholami Z, Shaffer D, Stone S, Bayer S, Wray C, Bogden R, Dayananth P, Ward J, Tonin P, Narod S, Bristow PK, Norris FH, Helvering L, Morrison P, Rasteck P, Lai M, Barrett IC, Lewis C, Neuhausen S, Cannon-Albright L, Goldgar D, Wiseman R, Kamb A, Skolnick MH. A strong candidate for the breast and ovarian cancer susceptibility gene BRCAl. Science 1994;266:66-71.

2. Wooster R, Bignell G, Lancaster J, Swift S, Seal S, Mangion J, Collins N, Gregory S, Gumbs C, Micklem G. Identification of the breast cancer susceptibility gene BRCA2. Nature 1995;378:789-792.

3. Caskey, CT. Presymptomatic diagnosis: A first step toward genetic health care. Science 1993;262:48-49.

4. American Society of Human Genetics Ad Hoc Committee on Breast and Ovarian Cancer Screening. Statement of the American Society of Human Genetics on genetic testing for breast and ovarian cancer predisposition. Am J Hum Genet 1994;55:i-iv.

5. National Advisory Council for Human Genome Research. Statement on the use of DNA testing for presymptomatic identification of cancer risk. JAMA 1994;271:785.

6. Biesecker BB, Boehnke M, Calzone K, Markel DS, Garber JE, Collins FS, Weber BL. Genetic counseling for families with inherited susceptibility to breast and ovarian cancer. JAMA 1993;269:1970-1974 .

7. Burke W, Daly M, Garber J, Botkin J, Kahn MJ, Lynch P, McTiernan A, Offit K, Perlman J, Petersen G, Thomson E, Varricchio C. Recommendations for follow-up care of individuals with an inherited predisposition to cancer. II. BRCA1 and BRCA2. Cancer Genetics Studies Consortium. JAMA 1997;277:997-1003.

8. Friedman LA, Webb JA, Richards CS, Lynch GR, Kaplan AL, Brunicardi FC, Plon SE. Psychological impact of negative BRCAl mutation results in Ashkenazim. Genetics in Medicine 1998;3:74-79.

9. Richards CS, Ward PA, Roa BB, Friedman LC, Boyd AA, Kuenzli G, Dunn JK, Plon SE. Screening for $185 \mathrm{deLAG}$ in the Ashkenazim. Am J Hum Genet 1997;60(5):1085-1098.

10. Lalloo F, Cochrane S, Bulman B, Varley J, Elles R, Howell A, Evans DG. An evaluation of common breast cancer gene mutations in a population of Ashkenazi Jews. J Med Genet 1998;35(1):10-12.

11. Lynch HT, Lemon SJ, Durham C, Tinley ST, Connolly C, Lynch JF, Surdam I, Orinion E, Slominski-Caster S, Watson P, Lerman C, Tonin P, Lenoir G, Serova O, Narod S. A descriptive study of BRCA1 testing and reactions to disclosure of test results. Cancer 1997;79:2219-2228.

12. Lerman C, Narod S, Schulman K, Hughes C, Gomez-Caminero A, Bonney G, Gold K, Trock B, Main D, Lynch J, Fulmore C, Snyder C, Lemon SJ, Conway $T$, Tonin $P$, Lenoir $G$, Lynch $H$. BRCAl testing in families with hereditary breast-ovarian cancer. A prospective study of patient decision making and outcomes. JAMA 1996;275:1885-1892.

Georgia L. Wiesner, MD Department of Genetics and the Center for Human Genetics Case Western Reserve University and University Hospitals of Cleveland 